\title{
Aneurysm Clipping and Outcome for Hunt \& Hess Grade 4, 5 Subarachnoid Hemorrhage-A Literature Review
}

\author{
Kalyan Bikram Shah', Lukui Chen ${ }^{*}$, Li Bing Qian'1, Sudeep Shrestha², Sandip Kumar Jaiswal ${ }^{3}$ \\ ${ }^{1}$ Department of Neurosurgery, Affiliated Zhong Da Hospital, Medical School of Southeast University, Nanjing, China \\ ${ }^{2}$ Department of Neurosurgery, Second Affiliated Hospital of Zhejiang University, Medical School of Zhejiang University, \\ Hangzhou, China \\ ${ }^{3}$ Department of Neurology, Affiliated Zhong Da Hospital, Medical School of Southeast University, Nanjing, China \\ Email: dr.kalyanbikramshah@yahoo.com,sdpsth@hotmail.com,drkumarsandip@yahoo.com,122490853@qq.com, \\ *neuro_clk@hotmail.com
}

How to cite this paper: Shah, K.B., Chen, L.K., Qian, L.B., Shrestha, S. and Jaiswal, S.K. (2018) Aneurysm Clipping and Outcome for Hunt \& Hess Grade 4, 5 Subarachnoid Hemorrhage-A Literature Review. Open Journal of Modern Neurosurgery, 8, 215-232.

https://doi.org/10.4236/ojmn.2018.82018

Received: March 13, 2018

Accepted: April 9, 2018

Published: April 12, 2018

Copyright $\odot 2018$ by authors and Scientific Research Publishing Inc. This work is licensed under the Creative Commons Attribution International License (CC BY 4.0).

http://creativecommons.org/licenses/by/4.0/

\begin{abstract}
"Subarachnoid Hemorrhage is non-traumatic nasty bleeding into the subarachnoid area, the territory between the arachnoid and the piamater of the central nervous system showing prompt developing signs of neurological sequelae". It is one among the neurological emergencies which is a very distressing cerebrovascular disease with complicated mechanisms that risks brain perfusion and its function, having higher morbidity and mortality rates. Its mortality rate is still ranged between $8.3 \%$ and $66.7 \%$, with noticeable regional variations, beside recent advances in treatment approaches. The incidence of SAH among the population of $2-22.5 / 100,000$ was reported with a minimum of $60 \%$ of aneurysm ruptures occurring amid ages of 40 and 60 years with 3:2 male:female ratio. The rupture risks for unruptured aneurysms are increased by the issues like present smokers, larger size of aneurysm, and amid young population. The surgical treatment decision should be contemplated upon factors such as aneurysm's size, aneurysm's location, patient's illness history, and surgeon's operative experiences. Latest technical progresses in imaging techniques, increased consideration of illness history, more awareness of incidences of aneurysms and use of micro neurosurgery, have raised the chance for detection of subarachnoid hemorrhage (SAH) and possible better outcomes with surgical management. Factors that may affect outcome include age, size and site of aneurysm, interval between ictus and surgery, CT Fisher Grade \& Hunt and Hess Grading earlier to surgery, \& Glasgow Coma Scale at the while of discharge. The studies here support the wide spread concept that surgical clipping of SAH for Hunt and Hess Grade 4, $5 \mathrm{SAH}$, which is also
\end{abstract}


considered as poor Grade SAH stipulates an effective treatment if done earlier provides better outcome.

\section{Keywords}

Aneurysm, Subarachnoid Hemorrhage, Hunt \& Hess Grading, Clipping, Outcome

\section{Introduction}

\subsection{Subarachnoid Hemorrhage (SAH)}

SAH is a very distressing cerebrovascular disease among neurological emergencies with complicated mechanisms which risks brain perfusion and its function, having higher morbidity and mortality rates [1] [2] [3] [4]. The recent updated definition of a SAH states that "it is non-traumatic nasty bleeding into the subarachnoid area, the territory between the arachnoid and the piamater of the central nervous system showing prompt developing signs of neurological sequelae" [5]. Mortality rate is still ranged between $8.3 \%$ and $66.7 \%$, with noticeable regional variations, beside recent advances in treatment approaches [6] [7]. The incidence of SAH among the population of $2-22.5 / 100,000$ was reported with a minimum of $60 \%$ of aneurysm ruptures occurring amid ages of 40 and 60 years with 3:2 male:female ratio [4] [8] [9]. $80 \%$ - 90\% of aneurysms are situated in the anterior cerebral circulation, middle cerebral arteries and anterior \& posterior communicating arteries [10]. The rest $10 \%-20 \%$ aneurysms are situated in the posterior cerebral circulation [10]. As the prognosis is poor, case fatality by 1 -month is as high as $35 \%$ [2]. Among those who survive, one-third of them need lifetime care, with remaining third shows cognitive impairment and dysfunctional state affecting the quality of life [11]. Ruptured aneurysms in the basal cerebral arteries has roughly $85 \%$ of non-traumatic SAH, with $45 \%$ mortality rate and $25 \%$ morbidity rate within 30 days [4] [5] [6].

The classical presentation of acute aneurysmal rupture is the prompt arrival of a severe headache, often explained as the "worst headache of my life", by preceding nausea, vomiting, syncope and slow deterioration in the level of consciousness [12] [13]. The risk factors for developing aneurysms are HTN (Hypertension), cigarette smoking, atherosclerosis, family history of CVD (Cerebrovascular Diseases), it is more predominant among females, and postmenopausal women [14]. The rupture risks for unruptured aneurysms are increased by the issues like present smokers, larger size of aneurysm, and amid young population [15]. Primarily the ruptured aneurysms deposit blood into the subarachnoid space between arachnoid and piamater, but after RBC (Red Blood Cells) breakdown and further degradation it deposits hemoglobin. RBC breakdown products such as methemoglobin, heme and hemin triggers Toll Like Receptors 4 that indicates inflammatory cascades which damages the brain [16] [17]. 
Hunt and Hess Grade 4 \& 5 SAH patients involve $20 \%$ to $30 \%$ of population having SAH [8] [18]-[23]. If SAH patients are presented with rebleeding, intracerebral hematoma, and Severe vasospasm of cerebral arteries which primes to further more grave consequences like DCI (delayed cerebral ischemia) leading to Delayed ischemic neurologic deficit [24] [25]. So, timely diagnosis and early surgical treatment further preventing complications are the predictors of better outcome. Here, we will focus more on earlier surgical treatment i.e. Aneurysm Clipping and its outcome. The objective of this review is to study the outcome of Aneurysm clipping for Hunt \& Hess grade 4, 5 subarachnoid Hemorrhages which are considered as poor Grades for early micro neurosurgery and comparing different studies with both 4, 5 Hunt \& Hess Grading of SAH.

\subsection{Methods}

Relevant studies focusing Subarachnoid hemorrhage's surgical treatment and its outcomes were searched on online databases: PubMed, EBSCO and Scopus, using key words "Subarachnoid hemorrhage", "Aneurysm”, "Clipping”, "Surgery", "Outcome" and "Hunt and Hess" in various combinations, such as "Aneurysm clipping", "Surgical outcome", "Outcome for Hunt and Hess grading", "Subarachnoid hemorrhage's outcome". In this review article, we have tried to review \& compile the clinical outcome of Aneurysm Clipping for Hunt and Hess 4, 5 Subarachnoid hemorrhage, which are considered to be Poor grades. Keywords being used in this review article to find this article and also the abbreviations used are provided within the article.

\subsection{Aneurysm Clipping}

The clipping across aneurysm neck to exclude from systemic circulation is ration for aneurysm surgery. The first surgery on brain aneurysm was performed by Norman Dott in 1933 [26]. In 1937 Walter Dandy applied silver clip for posterior communicating artery, and is still considered Gold standard for both ruptured and unruptured aneurysms [27]. With advent of new technologies i.e. operative microscope, development of the newer versions of Aneurysm Clips modified to present days' titanium clips, clips with springs which were more effective for the aneurysm surgery outcomes. The choice of a particular clip is centered on the size and where the aneurysm is located. Usually surgical clipping relates to the exposure of the aneurysm neck through craniotomy and excluding all abnormal vascular wall from the circulation by single or multiple clips. Basic principles of Aneurysm clippings are isolation of the Aneurysm from active circulation and maintaining parent vessel's veracity and patency. The base of Aneurysm clipping surgeries depends upon proper aneurysmal neck exposure [28].

\section{Diagnosing SAH}

SAH is diagnosed upon the foundation of History, clinical backgrounds and radiologically. Clinical condition is assessed with G.C.S (Glasgow coma scale) and 
amount of hemorrhage is graded in CT with CT Fischer Scale \& modified CT Fischer scale (Table 1), CTA, LP is opted for negative CT scan \& false-positive clinical signs. DSA is further done if aneurysms are small \& deep located which are difficult to detect on CT or CTA. The Glasgow coma scale, CT and LP are useful for diagnosing SAH, whereas CTA \& DSA shows bleeding aneurysm for further establishing SAH.

\subsection{Glasgow Coma Scale}

The assessment of coma in neurological patients is performed by Glasgow coma scale. It was formulated by Graham Teasdale and Bryan J. Jennett, both Neurosurgery professors from Institute of neurological Sciences, University of Glasgow published the Glasgow coma scale in 1974 [29]. It focuses on an unfailing and unbiased method of assessment of level of consciousness till date. It consists of three basic components of response of consciousness and is based on eye opening, verbal and motor responses. A total of 15 points is advocated out of them four points were given for eye response, five points for verbal response \& six points for motor responses each, with a maximum score of 15 and a minimum score of 3.

Eye opening response points in details are as follows; one point is given for no eye opening at all, two points are given for pain stimuli eye opening, three points are given for eye opening to speech and four points for natural eye opening.

Verbal response points in details are as follows: one point is given for no verbal response at all, two points are given for incomprehensible sound, three points are given for inappropriate words and four points for confused state and five points for fully oriented patients.

Motor response points for eliciting are as follows in details: one point is given for no motor response at all, two points are given for Decerebrate posturing, three points are given for Decorticate posturing, four points for Withdrawal from pain stimuli, five points for Localization to pain, and six points for the patients who fully obeys given commands [29].

\subsection{CT Fischer Grading (Table 1)}

The Fisher grade was established in 1980 and is applied in predicting the risks of onset of vasospasm after SAH on the foundation of quantity of blood seen on CT scan [30].

Table 1. CT fischer grading.

\begin{tabular}{cl}
\hline Grade & \multicolumn{1}{c}{ Computed Tomography Findings: } \\
\hline 1 & No Hemorrhage \\
2 & Diffused thin film of subarachnoid bleed (vertical films $\leq 1 \mathrm{~mm}$ ) \\
3 & Localized clot or thick film of subarachnoid bleed (vertical layers $\geq 1 \mathrm{~mm})$ \\
4 & ICH or IVH with diffuse or subarachnoid bleed \\
\hline
\end{tabular}

ICH-Intracranial Hemorrhages, IVH-Inter ventricular Hemorrhages. 


\subsection{Computed Tomography (CT)}

As hyperdense signal on CT scan suggests extravagated blood in subarachnoid space, hence CT scanning is considered choice of Investigation. And the bleed, its spread often advises the position \& extent of hemorrhage in ruptured aneurysms. CT studies can often show negative in $\sim 2 \%$ of the patients having SAH, so, it's possible for a false-negative SAH diagnosis on CT [31].

\subsection{Indication for Lumbar Puncture (LP)}

Among patients with a definite clinical history and suggestive negative brain imaging advocates need for lumbar puncture. Which when performed after at least $12 \mathrm{~h}$ of clinical presentation provides CSF a yellow tinge known as $\mathrm{X}$ anthochromia after centrifugation with spectrophotometry, resulted from hemoglobin breakdown products [32].

\subsection{CT Angiography (CTA) (Figure 1)}

Since CT Angiography is an investigation of higher sensitivity and near accuracy it gives better description of the morphology, orientation, neck size, adjacent vessels, and any additional aneurysms, if done quickly provides with better diagnosis of SAH which guides towards decision making for further management.

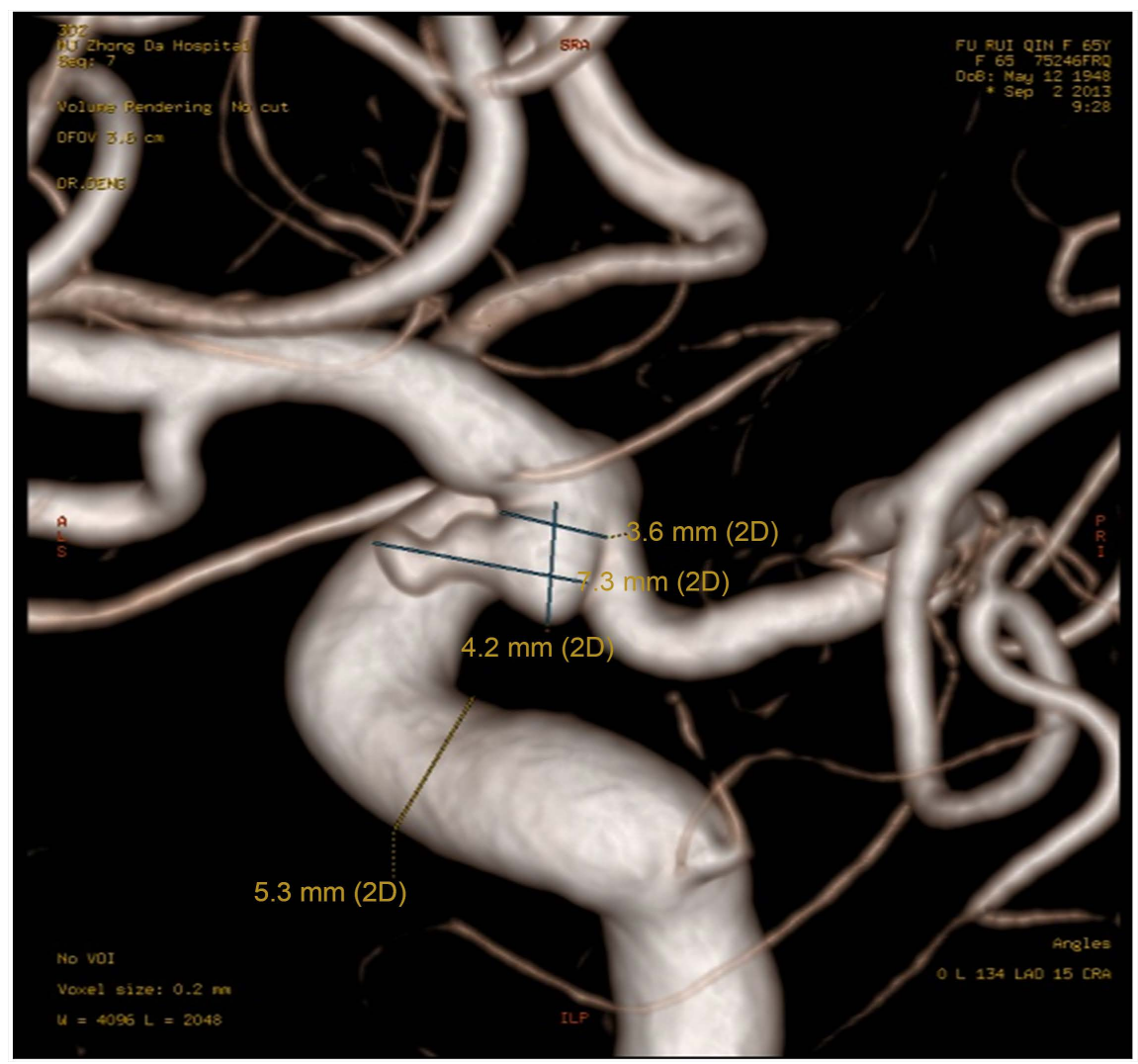

Figure 1. 3D CTA (Three dimensional reconstruction of Computed tomographic angiography) for PCoA (Posterior communicating artery) Aneurysm. [Photo Courtesy: Zhong Da Hospital, Nanjing, China]. 
[33]. Westerlaan et al. in their meta-analysis suggested that CT angiography should be considered as a prime investigation among patients with $\mathrm{SAH}$ [34].

\subsection{Digital Subtraction Angiography (DSA)}

In the cases when CTA not able to detect the origin of SAH, then DSA (Digital subtraction angiography) is indicated, as CTA limits detection of small SAH and those adjoining the skull base [35] [36]. AHA/ASA (American Heart Association/American Stroke Association) guidelines for managing aneurysmal SAH advocates DSA as first choice of Investigation [37].

\section{Surgical Indication}

Diagnosed cases of SAH with deterioration by lower points on Glasgow Coma Scale \& Lower CT Fischer scores [25] [26].

\section{Technique of Aneurysm Clipping}

Detailed interpretation of clinical signs \& symptoms, CT, CTA, DSA are evaluated for no. of aneurysm, location and size. Additional factors like hematoma formation, mass effect, brain herniation, hydrocephalus, vasospasms \& rupture of aneurysms are also assessed. Thereby allowing surgeons to further plan surgery as for proper approaches for incision, craniotomy \& precautions to be taken during surgery. Prioritizing measures should be taken for clipping ruptured aneurysm, doing surgery for already ruptured, larger aneurysm \& irregular aneurysms. Craniotomies are mostly done at the similar side of ruptured aneurysm. After general anesthesia, cases are positioned supine with head held in Mayfield at proper angle. Bolus mannitol infusion of $8-12 \mathrm{mg} / \mathrm{kg}$ is given before incision, to access more subarachnoid space easing the surgery. Lumbar drainage of CSF is also used for brain relaxation before beginning surgery. After relevant craniotomy for particular type of aneurysm \& by location, bone drilling is performed using a 5-mm burr of high-speed drills with adequate irrigation \& bone removal which minimizes retraction. Surgicel is applied between cottonoid and brain to prevent the cottonoid sticking the brain which might contribute to contusion of the cortex and also hydrocephalus which may occur after SAH while cotton removal. surgery is then proceeded after opening dura and reaching further and exposing the aneurysm and clipping it, before doing so temporary clip is applied which aid permanent aneurysm clipping, which can only be kept for a maximum of 3 minutes. Lamina terminalis is opened in almost all cases of $\mathrm{SAH}$ before dissecting aneurysm with the target to relax brain tissue and further providing more space for efficient maneuver. If gyrus rectus resection is a must, utmost attention should be given not to expand into the contralateral gyrus rectus as it may relate to memory loss. Intraoperative micro-Doppler probe is used in most of the cases. After clipping is done the vault of already clipped aneurysm is pierced with a needle to check if the dome is excluded from the circulation. Papaverine is added to irrigate since the start of the surgery and is also applied to 
the exposed arteries after clipping is done. Small aneurysms which cannot be clipped are wrapped with thin cottonoid arranged like cadger to permit fibrosis (Figure 2 Shows Aneurysm Clipping).

\section{Hunt and Hess Grading Scale}

\section{Hunt \& Hess Scale}

The Hunt and Hess scale was established in 1968 as a grading system to forecast clinically the prognosis and outcome among patients having SAH. A higher grade foresees a lowly outcome and less possibility of survival among SAH population.

Hunt and Hess Grading Scale is further elaborated in Table 2 [38] [39].

\section{Clinical Outcome}

Glasgow Outcome scale is a grading system for severity of disability descripted in the context of recovery from certain brain injuries (both traumatic and non-traumatic i.e. SAH). It was first mentioned by Jennett \& Bond in 1975. There are five categories of the Glasgow coma scale which permits forecasting rehabilitation on a long-term course of the illness [40].

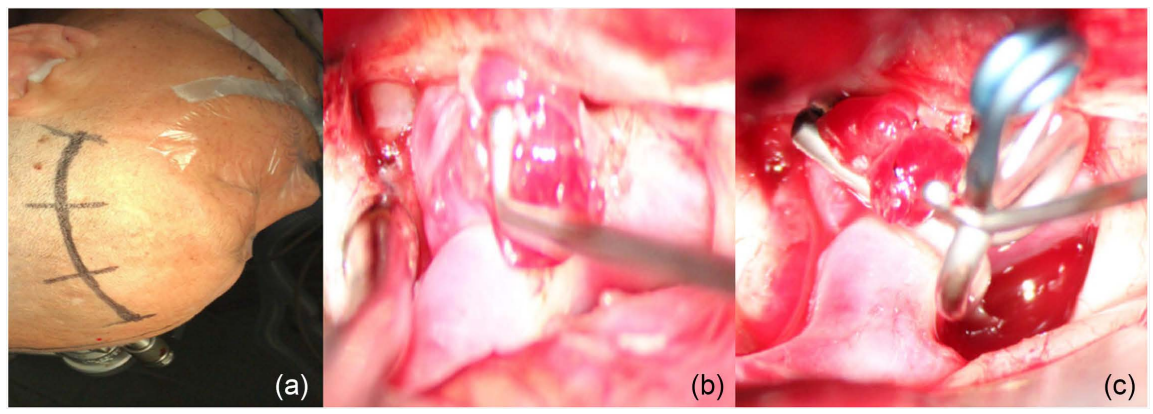

Figure 2. (a) INCISION Approach for the Surgery-Lateral Supraorbital Approach; (b) PCoA (Posterior communicating artery) Aneurysm before clipping; (c) PCoA (Posterior communicating artery) Aneurysm after clipping. [Photo courtesy-Zhong da Hospital, Nanjing, China]。

Table 2. Hunt and hess grading.

\begin{tabular}{cl}
\hline Grades & \multicolumn{1}{c}{ Criteria } \\
\hline 1 & Asymptomatic, mild headache, slight nuchal rigidity \\
2 & $\begin{array}{l}\text { Moderate to severe headache, nuchal rigidity, no neurological deficit other than } \\
\text { cranial nerve palsy }\end{array}$ \\
3 & Drowsiness, confusion, mild focal neurological deficit \\
4 & Stupor, moderate to severe hemiparesis \\
5 & Deep Coma, decerebrate posturing, Moribund appearance
\end{tabular}

${ }^{*}$ Serious systemic illness such as severe atherosclerosis, hypertension, diabetes, chronic pulmonary disease, and severe vasospasm found on CTA (Computed Tomography Angiography), marks in placing the patient in the next less favorable category. 
Outcome is mainly based upon GOS (short term Outcome) as the neurological outcome is regarded bestowing to it. GOS Score of 4, 5 is considered good outcome \& score of 2, 3 is regarded as poor outcomes.

Table 3 illustrates Glasgow Outcome Scale in detail [40].

mRS \& Barthel's Index which are also used for further functional disability and illustrates long term outcome. Factors that may affect outcome include age, size and site of aneurysm, interval between ictus and surgery, $\mathrm{H} \& \mathrm{H}$ Grades at surgery, CT Fisher scale \& GOS at the time of discharging the patient from hospital. Clinical Outcome after discharging the patient from the hospital and in the follow-ups, later, is generally assessed bestowing to the GOS (Glasgow Outcome Scale). Here below are few compilations of previous researches i.e outcome reports by various authors focused on $\mathrm{H} \& \mathrm{H}$ Grade 4, 5.

Retrospective study of 1196 patients undergoing Surgical clipping by Gupta et al. 2011, out of the total, only 165 patients were placed in poor grade [41]. Among 165 patients in poor grade, Ninety-Nine patients were in $\mathrm{H}$ and $\mathrm{H}$ Grade 4 and Sixty-Six patients were in Grade 5 with percentage of patients in $\mathrm{H} \& \mathrm{H}$ Grade 4 to be $60 \%$ \& H \& H Grade 5 to be $40 \%$. Long-term results were limited only to 39 patients as the patient's data for rest were not obtainable in random follow-ups. The long-term outcome was assessed by GOS for a period of Eight to Ninety-Two months' range and the outcomes are detailed as follows. H \& H Grade 4 (Twenty-Seven Patients): GOS 5 score-Twelve patients, 4 Score-Four patients, 3 Score-Ten patients, 2 Score-Zero patient, 1 score-One patient; H \& H Grade 5 (Twelve patients): GOS Score5-Five patients, Score 4-Six patients, score 3, 2-Zero patient \& Score 1-one patient respectively. Total patients-Thirty Nine (for both H \& H Grade 4, 5): GOS Grades: Grade 5-Seventeen patients (43.6\%), Grade 4-Ten patients (25.6\%), Grade 3-Ten patients, Grade 2-Zero patient, Grade 1 -Two patients (5.1\%). The authors found significant near normal recovery among patients with Grade 4, $5 \mathrm{SAH}$ in long-term follow-up which suggests that surgery must not be avoided in those patients just as because of more surgical complications among $\mathrm{H} \& \mathrm{H}$ Grade 4, 5 SAH because better outcomes among those patients with clipping was reported in their research [41].

Prospective study by Gupta et al. 2014 [42] on aneurysm clipping in a Long-term outcome for the Survived patients. They took 61 total patients for Hunt \& Hess 4, 5 Grades with a follow-up of Twelve months for Outcome Analysis.

Table 3. GCOS (Glasgow coma outcome scale).

\begin{tabular}{cl}
\hline Scale & \\
\hline 1 & Death \\
2 & Persistent Vegetative state (Lack of cortical functions) \\
3 & Severe Disability (Always need assistance with daily activities) \\
4 & Moderate disability (Disabled but Independent for daily activities) \\
5 & Good recovery (Normal daily life with minor deficits) \\
\hline
\end{tabular}


GOS Grade 4, 5 patients i.e. good outcome patients were further followed up post operatively after six to Twenty-four months. Amongtotal of H \& H Grade 4, 5 patients, there were Forty-seven patients for $\mathrm{H} \& \mathrm{H}$ Grade 4, and Fourteen patients for $\mathrm{H} \& \mathrm{H}$ Grade 5. The final outcome was based on GOS and their Outcome Analysis are as follows: $\mathrm{H} \& \mathrm{H}$ Grade 4-Forty-seven patients were found to be GOS $(4,5)$-Thirty-six patients, GOS $(2,3)$-Eleven patients. $\mathrm{H} \& \mathrm{H}$ Grade 5-Fourteen patients: GOS (4, 5)-Fourteen patients, GOS (2, 3)-Four patients. Which reveals a good outcome (GOS 4 and 5) being seen in majority of the cases of H \& H Grade 4, 5 and strongly correlates with the GOS at discharge irrespective of the period of follow up [42].

Retrospective study on outcome based on GOS for $\mathrm{H} \& \mathrm{H}$ Grade 4, $5 \mathrm{SAH}$ with intracerebral hematoma was done by Chen et al. [43]. Total number of patients was 18 \& GOS assessment was done by postoperative follow-up for 6 - 36 months'. Out of 18 total patients, 12 patients were of $H$ and $H$ grade 4 and 6 patients were of grade 5. Fifteen cases were operated within 24 hours of onset of SAH and three cases were operated after 24 hours, who had poor outcomes. The final outcome shows, four case out of Eighteen patients were found with favorable outcomes (GOS 4,5), four case who were severely disabled (GOS 3), six case were in vegetative state (GOS 2), and Four cases were dead (GOS 1). Chen et al.'s study suggests that $\mathrm{H} \& \mathrm{H} 4,5$ Grade $\mathrm{SAH}$ patients along with Intracerebral hematoma, that if surgery is done within first 24 hours of onset of SAH may progress better prognosis [43].

Table 4 illustrates summary of results for aneurysm clipping outcome by various authors.

\section{Complications}

Pre-surgical complications of SAH are, increased Intracranial Pressure, Intracranial Hematoma, Mass effect, Brain herniation's, Hydrocephalus, seizures and cerebral vasospasm with Hyponatremia as a major post-surgical complication. Few of them are discussed here below:

Table 4. Table Showing compilation of few previous studies on Hunt \& Hess Grade 4, 5 Subarachnoid hemorrhages.

\begin{tabular}{|c|c|c|c|c|}
\hline No. & Authors & No. of Cases & $\begin{array}{l}\text { Follow Up } \\
\text { (months) }\end{array}$ & Outcome by GOS Scale (Glasgow Outcome Scale) \\
\hline 1. & $\begin{array}{l}\text { Gupta et al. } 2011 \\
\text { (A Retrospective Study) }\end{array}$ & $\begin{array}{l}\text { Grade } 4-27 \text { patients } \\
\text { Grade } 5-12 \text { patients }\end{array}$ & $8-92$ & $\begin{array}{l}\text { H \& H Grade } 4 \text { ( } 27 \text { Patients: GOS } 5 \text { score }-12 \text { patients, } 4 \text { score }-04 \text { patients, } \\
3 \text { score }-10 \text { patients, } 2 \text { score }-00 \text { patients, } 1 \text { score }-01 \text { patients; H \& H Grade } \\
5 \text { ( } 12 \text { patients): Score } 5-05 \text { patients, score } 4-06 \text { patients, score } 3,2-00 \\
\text { patients, score } 1-01 \text { patients respectively. } \\
\text { Total patients-39 (both H \& H Grade } 4,5) \text { GOS Grades: Grade } 5-17 \text { pts. } \\
(43.6) \% \text {, grade } 4-0(25.6 \%) \text {, grade } 3-10 \text { patients, grade } 2-00 \text { patients, } \\
\text { Grade } 1-02 \text { pts. }(5.1 \%)\end{array}$ \\
\hline 2. & $\begin{array}{l}\text { Gupta et al. } 2014 \\
\text { (A Prospective Study) }\end{array}$ & 61 & 12 & $\begin{array}{l}\text { H \& H Grade 4: } 47 \text { patients: GOS }(4,5)-36 \text { patients, GOS }(2,3)-11 \text { patients, } \\
\text { H \& H Grade 5: } 14 \text { patients: GOS }(4,5)-14 \text { patients, GOS }(2,3)-4 \text { patients. }\end{array}$ \\
\hline 3. & $\begin{array}{l}\text { Chen Junhui et al. } 2016 \\
\text { (A Retrospective Study) }\end{array}$ & 18 & $6-36$ & $\begin{array}{l}4 \text { cases were favorable (GOS } 1) ; 4 \text { cases were severely disabled (GOS } 3 \text { ) } \\
\& 6 \text { cases were in vegetative state (GOS } 2 \text { ); } 4 \text { cases were dead (GOS } 1) \text {. }\end{array}$ \\
\hline
\end{tabular}


HCP (Hydrocephalus) is a severe and typical complication in the clinical course of SAH. Most recent studies show percentage of HCP incidence among SAH patients to be about $20 \%-30 \%$. HCP occurs in the early course (first 3 days-acute or after 4 - 14 days-subacute) of SAH in about one fifth of patients, and chronic hydrocephalus occurs in $10 \%-20 \%$ of patients after 2 weeks. HCP alters patient's neurologic function failing better functional outcomes, mainly with IVH (Intraventricular hemorrhage), even after the key SAH been managed. [44]

Previous clinical studies by (Guresir et al. \& Niemann et al.) shows ICH to be $4 \%$ to $43 \%$ of the total cases of SAH [45] [46]. Reported Deaths from SAH patients with $\mathrm{ICH}$ was ranged from $38 \%$ to $58 \%$ [47]. Previous studies show SAH patients with $\mathrm{ICH}$ have more severe clinical progress and lowlier functional outcome in comparison to patients not having ICH [48] [49] [50].

Seizures are found to be more common among younger age patients, with $\mathrm{ICH}$ (Intracranial hemorrhage), MCA aneurysms, and lower grade SAH [51]-[59]. In a latest prospective analysis, Cerebral infarction, Subdural Hematoma, vasospasm, and hydrocephalus at exposition have been linked to risks of seizures later [60] [61]. But, In most of earlier studies, Seizure at exposition of SAH do not relate with seizures later after aneurysm is repair [55] [61] [62] [63], and those seizure events were rather associated to unusual posturing [64], raised intracranial pressure or herniation rather than real seizures [65] [66]. Patients after treated for SAH with surgical clipping presents with up to $26 \%$ of late seizures which had been reported from previous studies [67].

$\mathrm{CV}$ is a grave complication of SAH experienced by SAH survivors which is the "narrowing of arteries within the subarachnoid space of the brain" [68] [69] [70]. If it persists, less blood flows in troubled areas of the brain, leading to delayed cerebral ischemia [71]. CV is portrayed by gradual spasm of cerebral arteries commencing no prior to day three succeeding hemorrhage and reaching peak at a week [72]. Among 20\% - 30\% of patients, CV primes to infarction and delayed cerebral ischemia [73]. Though the exact etiology of CV remains unknown, spasm causing and neuro inflammatory substances being produced from the blood breakdown in subarachnoid space are believed to initiate the course [74]. Triple-H Therapy i.e. therapy for Hypertension, Hypervolemia and Hemodilution stays the utmost effective regime for avoidance and management of ischemic neurological deficits caused by cerebral vasospasm.

Rebleeding from grade 4, $5 \mathrm{SAH}$ are presented with high mortality and are very common, which usually happens before Aneurysm Clipping [75] [76] [77]. SAH Patients with larger aneurysms $(>10 \mathrm{~mm})$ have a higher jeopardy of rebleeding before Surgery [78]. Few studies show that early rebleeding happensmainly within first 24 hour of SAH occurrence, especially in the initial $6-12$ hour i.e. also called ultra-early, when utmost danger of rebleeding is present [79] [80] [81]. To evade high mortality and rebleeding before aneurysm surgery, assertive and ultra-early Clipping surgery among patients with lower grade SAH is 
recommended [82] [83] [84].

Hyponatremia is common among SAH patients, as several studies suggest its incidence of more than $50 \%$ of total SAH [85] [86]. It is an electrolyte disturbance related to numerous neurologic sequelae, i.e. seizures, altered mental status and coma. Common reasons of hyponatremia after SAH are SIADH (Syndrome of inappropriate anti-diuretic hormone secretion) \& CSWS (Cerebral salt wasting syndrome). The control protocol for SIADH is fluid limitation whereas in CSWS fluid is given [87]. In hyponatremia, the abnormal osmotic equilibrium triggers plasma to move towards the interstitial space from blood vessels causing cellular edema and reduced cell functioning [88] [89] [90] [91]. Increased intracranial pressure and brain edema usually occurs when Serum Sodium Level is acutely decreased to $(<125 \mathrm{mEq} / \mathrm{L})$ causing severe hyponatremia initiating a life threatening neurological sequelae [92] [93]. As Fast correction of hyponatremia may prime to CPM (central pontine myelinolysis), a cautious management of hyponatremia is therefore required [94].

\section{Conclusion}

The present study endorses several indicators for an outcome of Hunt \& Hess Grade 4, 5 SAH patients being treated with surgical clipping. Treatment of patients with Hunt \& Hess Grade 4, 5 SAH should be conceded promptly and uncompromisingly to evade further complications of SAH like rebleeding, seizure, ICH (Intracranial Hematoma), Cerebral Vasospasm and a probability of negative outcome. Careful detailed patient assessment workup and surgical treatment are indispensable for each patient for positive outcome.

\section{Acknowledgements}

Special thanks to prof. Chen Lu Kui for his proper guidance and to the coauthors for their help \& support throughout.

\section{Author Contributions}

All authors contributed equally.

\section{Declaration of Conflicting Interests}

None to be declared.

\section{References}

[1] Nagashima, H., Miwa, T., Horiguchi, T., Tomio, R., Nakagawa, Y. and Yoshida, K. (2018) Hyperperfusion after Clipping of Aneurysm: A Rare Entity. Journal of Stroke and Cerebrovascular Diseases, 27, 1425-1430. https://doi.org/10.1016/j.jstrokecerebrovasdis.2017.11.024

[2] Go, A.S., Mozaffarian, D., Roger, V.L., Benjamin, E.J., Berry, J.D., Blaha, M.J., et al. (2014) Heart Disease and Stroke Statistics-2014 Update: A Report from the American Heart Association. Circulation, 129, e28-e292. https://doi.org/10.1161/01.cir.0000441139.02102.80 
[3] Johnston, S.C., Selvin, S. and Gress, D.R. (1998) The Burden, Trends, and Demographics of Mortality from Subarachnoid Hemorrhage. Neurology, 50, 1413-1418. https://doi.org/10.1212/WNL.50.5.1413

[4] van Gijn, J., Kerr, R.S. and Rinkel, G.J.E. (2007) Subarachnoid Haemorrhage. The Lancet, 369, 306-318. https://doi.org/10.1016/S0140-6736(07)60153-6

[5] Sacco, R.L., Kasner, S.E., Broderick, J.P., Caplan, L.R., Connors, J.J.B., Culebras, A., et al. (2013) An Updated Definition of Stroke for the 21st Century: A Statement for Healthcare Professionals from the American Heart Association/American Stroke Association. Stroke, 44, 2064-2089. https://doi.org/10.1161/STR.0b013e318296aeca

[6] Dijkland, S.A., Roozenbeek, B., Brouwer, P.A., Lingsma, H.F., Dippel, D.W., Vergouw, L.J., et al. (2016) Prediction of 60-Day Case Fatality after Aneurysmal Subarachnoid Hemorrhage: External Validation of a Prediction Model. Critical Care Medicine, 44, 1523-1529. https://doi.org/10.1097/CCM.0000000000001709

[7] Nieuwkamp, D.J., Setz, L.E., Algra, A., Linn, F.H.H., de Rooij, N.K. and Rinkel, G.J.E. (2009) Changes in Case Fatality of Aneurysmal Subarachnoid Haemorrhage over Time, According to Age, Sex, and Region: A Meta-Analysis. The Lancet Neurology, 8, 635-642. https://doi.org/10.1016/S1474-4422(09)70126-7

[8] Kassell, N.F., Torner, J.C., Haley, E.C., Jane, J.A., Adams, H.P. and Kongable, G.L. (1990) The International Cooperative Study on the Timing of Aneurysm Surgery. Part 1: Overall Management Results. Journal of Neurosurgery, 73, 18-36. https://doi.org/10.3171/jns.1990.73.1.0018

[9] Gaberel, T., Magheru, C., Emery, E. and Derlon, J.-M. (2012) Antifibrinolytic Therapy in the Management of Aneurismal Subarachnoid Hemorrhage Revisited. A Meta-Analysis. Acta Neurochirurgica (Wien), 154, 1-9. https://doi.org/10.1007/s00701-011-1179-y

[10] Kundra, S., Mahendru, V., Gupta, V. and Choudhary, A.K. (2014) Principles of Neuroanesthesia in Aneurysmal Subarachnoid Hemorrhage. Journal of Anaesthesiology Clinical Pharmacology, 30, 328-337. https://doi.org/10.4103/0970-9185.137261

[11] Passier, P.E.C.A., Visser-Meily, J.M.A., van Zandvoort, M.J.E., Post, M.W.M., Rinkel, G.J.E. and van Heugten, C. (2010) Prevalence and Determinants of Cognitive Complaints after Aneurysmal Subarachnoid Hemorrhage. Cerebrovascular Diseases (Basel, Switzerland), 29, 557-563. https://doi.org/10.1159/000306642

[12] Linn, F.H., Rinkel, G.J., Algra, A. and van Gijn, J. (1998) Headache Characteristics in Subarachnoid Haemorrhage and Benign Thunderclap Headache. Journal of Neurology, Neurosurgery, and Psychiatry, 65, 791-793. https://doi.org/10.1136/jnnp.65.5.791

[13] Waga, S., Otsubo, K. and Handa, H. (1975) Warning Signs in Intracranial Aneurysms. Surgical Neurology, 3, 15-20.

[14] Ellamushi, H.E., Grieve, J.P., Jäger, H.R. and Kitchen, N.D. (2001) Risk Factors for the Formation of Multiple Intracranial Aneurysms. Journal of Neurosurgery, 94, 728-732. https://doi.org/10.3171/jns.2001.94.5.0728

[15] Juvela, S., Porras, M. and Poussa, K. (2000) Natural History of Unruptured Intracranial Aneurysms: Probability of and Risk Factors for Aneurysm Rupture. Journal of Neurosurgery, 93, 379-387. https://doi.org/10.3171/jns.2000.93.3.0379

[16] Ascenzi, P., Bocedi, A., Visca, P., Altruda, F., Tolosano, E., Beringhelli, T., et al. (2005) Hemoglobin and Heme Scavenging. IUBMB Life, 57, 749-759. https://doi.org/10.1080/15216540500380871

[17] Pradilla, G., Chaichana, K.L., Hoang, S., Huang, J. and Tamargo, R.J. (2010) In- 
flammation and Cerebral Vasospasm after Subarachnoid Hemorrhage. Neurosurgery Clinics of North America, 21, 365-379. https://doi.org/10.1016/j.nec.2009.10.008

[18] Kassell, N.F., Torner, J.C., Jane, J.A., Haley, E.C. and Adams, H.P. (1990) The International Cooperative Study on the Timing of Aneurysm Surgery. Part 2: Surgical Results. Journal of Neurosurgery, 73, 37-47. https://doi.org/10.3171/jns.1990.73.1.0037

[19] Hutchinson, P.J., Power, D.M., Tripathi, P. and Kirkpatrick, P.J. (2000) Outcome from Poor Grade Aneurysmal Subarachnoid Haemorrhage-Which Poor Grade Subarachnoid Haemorrhage Patients Benefit from Aneurysm Clipping? British Journal of Neurosurgery, 14, 105-109. https://doi.org/10.1080/02688690050004516

[20] Le Roux, P.D., Elliott, J.P., Newell, D.W., Grady, M.S. and Winn, H.R. (1996) Predicting Outcome in Poor-Grade Patients with Subarachnoid Hemorrhage: A Retrospective Review of 159 Aggressively Managed Cases. Journal of Neurosurgery, 85, 39-49. https://doi.org/10.3171/jns.1996.85.1.0039

[21] Zentner, J., Hoffmann, C. and Schramm, J. (1996) Results of Early Surgery in Poor-Grade Aneurysm Patients. Journal of Neurosurgical Sciences, 40, 183-188.

[22] Nowak, G., Schwachenwald, R. and Arnold, H. (1994) Early Management in Poor Grade Aneurysm Patients. Acta Neurochirurgica (Wien), 126, 33-37. https://doi.org/10.1007/BF01476491

[23] Sasaki, T., Sato, M., Oinuma, M., Sakuma, J., Suzuki, K., Matsumoto, M., et al. (2004) Management of Poor-Grade Patients with Aneurysmal Subarachnoid Hemorrhage in the Acute Stage: Importance of Close Monitoring for Neurological Grade Changes. Surgical Neurology, 62, 531-535.

https://doi.org/10.1016/j.surneu.2004.01.015

[24] Dossett, L.A., Heffernan, D., Lightfoot, M., Collier, B., Diaz, J.J., Sawyer, R.G., et al. (2008) Obesity and Pulmonary Complications in Critically Injured Adults. Chest, 134, 974-980. https://doi.org/10.1378/chest.08-0079

[25] Dossett, L.A., Dageforde, L.A., Swenson, B.R., Metzger, R., Bonatti, H., Sawyer, R.G., et al. (2009) Obesity and Site-Specific Nosocomial Infection Risk in the Intensive Care Unit. Surgical Infections, 10, 137-142. https://doi.org/10.1089/sur.2008.028

[26] Maurice-Williams, R.S. and Lafuente, J. (2003) Intracranial Aneurysm Surgery and Its Future. Journal of the Royal Society of Medicine, 96, 540-543. https://doi.org/10.1177/014107680309601106

[27] Chicoine, M.R. (2003) Microsurgery and Clipping: The Gold Standard for the Treatment of Intracranial Aneurysms. Journal of Neurosurgical Anesthesiology, 15, 61-63. https://doi.org/10.1097/00008506-200301000-00013

[28] Gross, B.A. and Du, R. (2013) Microsurgical Treatment of Ophthalmic Segment Aneurysms. Journal of Clinical Neuroscience, 20, 1145-1148.

https://doi.org/10.1016/j.jocn.2012.11.005

[29] Teasdale, G. and Jennett, B. (1974) Assessment of Coma and Impaired Consciousness. A Practical Scale. The Lancet (London, England), 2, 81-84. https://doi.org/10.1016/S0140-6736(74)91639-0

[30] Fisher, C.M., Kistler, J.P. and Davis, J.M. (1980) Relation of Cerebral Vasospasm to Subarachnoid Hemorrhage Visualized by Computerized Tomographic Scanning. Neurosurgery, 6, 1-9. https://doi.org/10.1227/00006123-198001000-00001

[31] van der Wee, N., Rinkel, G.J., Hasan, D. and van Gijn, J. (1995) Detection of Sub- 
arachnoid Haemorrhage on Early CT: Is Lumbar Puncture Still Needed after a Negative Scan? Journal of Neurology, Neurosurgery, and Psychiatry, 58, 357-359. https://doi.org/10.1136/jnnp.58.3.357

[32] Stieg, P.E. and Kase, C.S. (1998) Intracranial Hemorrhage: Diagnosis and Emergency Management. Neurologic Clinics, 16, 373-390. https://doi.org/10.1016/S0733-8619(05)70069-4

[33] Menke, J., Larsen, J. and Kallenberg, K. (2011) Diagnosing Cerebral Aneurysms by Computed Tomographic Angiography: Meta-Analysis. Annals of Neurology, 69, 646-654. https://doi.org/10.1002/ana.22270

[34] Westerlaan, H.E., van Dijk, J.M.C., van Dijk, M.J., Jansen-van der Weide, M.C., de Groot, J.C., Groen, R.J.M., et al. (2011) Intracranial Aneurysms in Patients with Subarachnoid Hemorrhage: CT Angiography as a Primary Examination Tool for Diagnosis-Systematic Review and Meta-Analysis. Radiology, 258, 134-145. https://doi.org/10.1148/radiol.10092373

[35] Kallmes, D.F., Layton, K., Marx, W.F. and Tong, F. (2007) Death by Nondiagnosis: Why Emergent CT Angiography Should Not Be Done for Patients with Subarachnoid Hemorrhage. American Journal of Neuroradiology, 28, 1837-1838. https://doi.org/10.3174/ajnr.A0809

[36] Moran, C.J. (2011) Aneurysmal Subarachnoid Hemorrhage: DSA versus CT Angiography-Is the Answer Available? Radiology, 258, 15-17. https://doi.org/10.1148/radiol.101911

[37] Bederson, J.B., Connolly, E.S., Batjer, H.H., Dacey, R.G., Dion, J.E., Diringer, M.N., et al. (2009) Guidelines for the Management of Aneurysmal Subarachnoid Hemorrhage: A Statement for Healthcare Professionals from a Special Writing Group of the Stroke Council, American Heart Association. Stroke, 40, 994-1025. https://doi.org/10.1161/STROKEAHA.108.191395

[38] Hunt, W.E., Meagher, J.N. and Hess, R.M. (1966) Intracranial Aneurysm. A Nine-Year Study. The Ohio State Medical Journal, 62, 1168-1171.

[39] Hunt, W.E. and Hess, R.M. (1968) Surgical Risk as Related to Time of Intervention in the Repair of Intracranial Aneurysms. Journal of Neurosurgery, 28, 14-20. https://doi.org/10.3171/jns.1968.28.1.0014

[40] Jennett, B. and Bond, M. (1975) Assessment of Outcome after Severe Brain Damage. The Lancet (London, England), 1, 480-484. https://doi.org/10.1016/S0140-6736(75)92830-5

[41] Gupta, S.K., Ghanta, R.K., Chhabra, R., Mohindra, S., Mathuriya, S.N., Mukherjee, K.K., et al. (2011) Poor-Grade Subarachnoid Hemorrhage: Is Surgical Clipping Worthwhile? Neurology India, 59, 212-217. https://doi.org/10.4103/0028-3886.79144

[42] Gupta, S.K., Chhabra, R., Mohindra, S., Sharma, A., Mathuriya, S.N., Pathak, A., et al. (2014) Long-Term Outcome in Surviving Patients after Clipping of Intracranial Aneurysms. World Neurosurgery, 81, 316-321. https://doi.org/10.1016/j.wneu.2013.01.034

[43] Chen, J., Zhu, J., He, J., Wang, Y., Chen, L., Zhang, C., et al. (2016) Ultra-Early Microsurgical Treatment within $24 \mathrm{~h}$ of SAH Improves Prognosis of Poor-Grade Aneurysm Combined with Intracerebral Hematoma. Oncology Letters, 11, 3173-3178. https://doi.org/10.3892/ol.2016.4327

[44] Garton, T., Keep, R.F., Wilkinson, D.A., Strahle, J.M., Hua, Y., Garton, H.J.L., et al. (2016) Intraventricular Hemorrhage: The Role of Blood Components in Secondary 
Injury and Hydrocephalus. Translational Stroke Research, 7, 447-451. https://doi.org/10.1007/s12975-016-0480-8

[45] Güresir, E., Beck, J., Vatter, H., Setzer, M., Gerlach, R., Seifert, V., et al. (2008) Subarachnoid Hemorrhage and Intracerebral Hematoma: Incidence, Prognostic Factors, and Outcome. Neurosurgery, 63, 1088-1093. https://doi.org/10.1227/01.NEU.0000335170.76722.B9

[46] Niemann, D.B., Wills, A.D., Maartens, N.F., Kerr, R.S.C., Byrne, J.V. and Molyneux, A.J. (2003) Treatment of Intracerebral Hematomas Caused by Aneurysm Rupture: Coil Placement Followed by Clot Evacuation. Journal of Neurosurgery, 99, 843-847. https://doi.org/10.3171/jns.2003.99.5.0843

[47] Tokuda, Y., Inagawa, T., Katoh, Y., Kumano, K., Ohbayashi, N. and Yoshioka, H. (1995) Intracerebral Hematoma in Patients with Ruptured Cerebral Aneurysms. Surgical Neurology, 43, 272-277. https://doi.org/10.1016/0090-3019(95)80013-7

[48] Otani, N., Takasato, Y., Masaoka, H., Hayakawa, T., Yoshino, Y., Yatsushige, H., et al. (2011) Clinical Characteristics and Surgical Outcomes of Patients with Aneurysmal Subarachnoid Hemorrhage and Acute Subdural Hematoma Undergoing Decompressive Craniectomy. World Neurosurgery, 75, 73-77. https://doi.org/10.1016/j.wneu.2010.10.021

[49] Abbed, K.M. and Ogilvy, C.S. (2003) Intracerebral Hematoma from Aneurysm Rupture. Neurosurgical Focus, 15, E4. https://doi.org/10.3171/foc.2003.15.4.4

[50] Crompton, M.R. (1962) Intracerebral Haematoma Complicating Ruptured Cerebral Berry Aneurysm. Journal of Neurology, Neurosurgery, and Psychiatry, 25, 378-386. https://doi.org/10.1136/jnnp.25.4.378

[51] Buczacki, S.J., Kirkpatrick, P.J., Seeley, H.M. and Hutchinson, P.J. (2004) Late Epilepsy Following Open Surgery for Aneurysmal Subarachnoid Haemorrhage. Journal of Neurology, Neurosurgery, and Psychiatry, 75, 1620-1622. https://doi.org/10.1136/jnnp.2003.026856

[52] Choi, K.-S., Chun, H.-J., Yi, H.-J., Ko, Y., Kim, Y.-S. and Kim, J.-M. (2009) Seizures and Epilepsy Following Aneurysmal Subarachnoid Hemorrhage: Incidence and Risk Factors. Journal of Korean Neurosurgical Society, 46, 93-98. https://doi.org/10.3340/jkns.2009.46.2.93

[53] Krishna, H., Wani, A.A., Behari, S., Banerji, D., Chhabra, D.K. and Jain, V.K. (2005) Intracranial Aneurysms in Patients 18 Years of Age or Under, Are They Different from Aneurysms in Adult Population? Acta Neurochirurgica (Wien), 147, 469-476. https://doi.org/10.1007/s00701-005-0481-y

[54] Lin, C.-L., Dumont, A.S., Lieu, A.-S., Yen, C.-P., Hwang, S.-L., Kwan, A.-L., et al. (2003) Characterization of Perioperative Seizures and Epilepsy Following Aneurysmal Subarachnoid Hemorrhage. Journal of Neurosurgery, 99, 978-985. https://doi.org/10.3171/jns.2003.99.6.0978

[55] Lin, Y.-J., Chang, W.-N., Chang, H.-W., Ho, J.-T., Lee, T.-C., Wang, H.-C., et al. (2008) Risk Factors and Outcome of Seizures after Spontaneous Aneurysmal Subarachnoid Hemorrhage. European Journal of Neurology, 15, 451-457. https://doi.org/10.1111/j.1468-1331.2008.02096.x

[56] Rhoney, D.H., Tipps, L.B., Murry, K.R., Basham, M.C., Michael, D.B. and Coplin, W.M. (2000) Anticonvulsant Prophylaxis and Timing of Seizures after Aneurysmal Subarachnoid Hemorrhage. Neurology, 55, 258-265. https://doi.org/10.1212/WNL.55.2.258

[57] Liu, K.C. and Bhardwaj, A. (2007) Use of Prophylactic Anticonvulsants in Neurologic Critical Care: A Critical Appraisal. Neurocritical Care, 7, 175-184. 
https://doi.org/10.1007/s12028-007-0061-5

[58] Ogden, J.A., Utley, T. and Mee, E.W. (1997) Neurological and Psychosocial Outcome 4 to 7 Years after Subarachnoid Hemorrhage. Neurosurgery, 41, 25-34. https://doi.org/10.1097/00006123-199707000-00008

[59] Ohman, J. (1990) Hypertension as a Risk Factor for Epilepsy after Aneurysmal Subarachnoid Hemorrhage and Surgery. Neurosurgery, 27, 578-581. https://doi.org/10.1227/00006123-199010000-00012

[60] Claassen, J., Peery, S., Kreiter, K.T., Hirsch, L.J., Du, E.Y., Connolly, E.S., et al. (2003) Predictors and Clinical Impact of Epilepsy after Subarachnoid Hemorrhage. Neurology, 60, 208-214. https://doi.org/10.1212/01.WNL.0000038906.71394.DE

[61] Hasan, D., Schonck, R.S., Avezaat, C.J., Tanghe, H.L., van Gijn, J. and van der Lugt, P.J. (1993) Epileptic Seizures after Subarachnoid Hemorrhage. Annals of Neurology, 33, 286-291. https://doi.org/10.1002/ana.410330310

[62] Byrne, J.V., Boardman, P., Ioannidis, I., Adcock, J. and Traill, Z. (2003) Seizures after Aneurysmal Subarachnoid Hemorrhage Treated with Coil Embolization. Neurosurgery, 52, 545-552. https://doi.org/10.1227/01.NEU.0000047672.25068.4A

[63] Viñuela, F., Duckwiler, G. and Mawad, M. (2008) Guglielmi Detachable Coil Embolization of Acute Intracranial Aneurysm: Perioperative Anatomical and Clinical Outcome in 403 Patients. Journal of Neurosurgery, 108, 832-839. https://doi.org/10.3171/JNS/2008/108/4/0832

[64] Diringer, M.N. (2009) Management of Aneurysmal Subarachnoid Hemorrhage. Critical Care Medicine, 37, 432-440. https://doi.org/10.1097/CCM.0b013e318195865a

[65] Deutschman, C.S. and Haines, S.J. (1985) Anticonvulsant Prophylaxis in Neurological Surgery. Neurosurgery, 17, 510-517. https://doi.org/10.1227/00006123-198509000-00021

[66] Gilmore, E., Choi, H.A., Hirsch, L.J. and Claassen, J. (2010) Seizures and CNS Hemorrhage: Spontaneous Intracerebral and Aneurysmal Subarachnoid Hemorrhage. The Neurologist, 16, 165-175. https://doi.org/10.1097/NRL.0b013e3181c7cd0b

[67] Hayashi, T., Hadeishi, H., Kawamura, S., Nonoyama, Y., Suzuki, A. and Yasui, N. (1999) Postoperative Anticonvulsant Prophylaxis for Patients Treated for Cerebral Aneurysms. Neurologia Medico-Chirurgica (Tokyo), 39, 828-833. https://doi.org/10.2176/nmc.39.828

[68] Wu, C.-T., Wong, C.-S., Yeh, C.-C. and Borel, C.O. (2004) Treatment of Cerebral Vasospasm after Subarachnoid Hemorrhage-A Review. Acta Anaesthesiologica Taiwanica, 42, 215-222.

[69] Rabinstein, A.A., Weigand, S., Atkinson, J.L.D. and Wijdicks, E.F.M. (2005) Patterns of Cerebral Infarction in Aneurysmal Subarachnoid Hemorrhage. Stroke, 36, 992-997. https://doi.org/10.1161/01.STR.0000163090.59350.5a

[70] Ma, J., Huang, S., Ma, L., Liu, Y., Li, H. and You, C. (2012) Endothelin-Receptor Antagonists for Aneurysmal Subarachnoid Hemorrhage: An Updated Meta-Analysis of Randomized Controlled Trials. Critical Care (London, England), 16, R198. https://doi.org/10.1186/cc11686

[71] Konczalla, J., Kashefiolasl, S., Brawanski, N., Lescher, S., Senft, C., Platz, J., et al. (2016) Cerebral Vasospasm and Delayed Cerebral Infarctions in 225 Patients with Non-Aneurysmal Subarachnoid Hemorrhage: The Underestimated Risk of Fisher 3 Blood Distribution. Journal of NeuroInterventional Surgery, 8, 1247-1252. https://doi.org/10.1136/neurintsurg-2015-012153 
[72] Bederson, J.B., Levy, A.L., Ding, W.H., Kahn, R., DiPerna, C.A., Jenkins, A.L., et al. (1998) Acute Vasoconstriction after Subarachnoid Hemorrhage. Neurosurgery, 42, 352-360. https://doi.org/10.1097/00006123-199802000-00091

[73] Kassell, N.F., Sasaki, T., Colohan, A.R. and Nazar, G. (1985) Cerebral Vasospasm following Aneurysmal Subarachnoid Hemorrhage. Stroke, 16, 562-572. https://doi.org/10.1161/01.STR.16.4.562

[74] Provencio, J.J. and Vora, N. (2005) Subarachnoid Hemorrhage and Inflammation: Bench to Bedside and Back. Seminars in Neurology, 25, 435-444. https://doi.org/10.1055/s-2005-923537

[75] Ransom, E.R., Mocco, J., Komotar, R.J., Sahni, D., Chang, J., Hahn, D.K., et al. (2007) External Ventricular Drainage Response in Poor Grade Aneurysmal Subarachnoid Hemorrhage: Effect on Preoperative Grading and Prognosis. Neurocritical Care, 6, 174-180. https://doi.org/10.1007/s12028-007-0019-7

[76] Naidech, A.M., Janjua, N., Kreiter, K.T., Ostapkovich, N.D., Fitzsimmons, B.-F., Parra, A., et al. (2005) Predictors and Impact of Aneurysm Rebleeding after Subarachnoid Hemorrhage. Archives of Neurology, 62, 410-416.

https://doi.org/10.1001/archneur.62.3.410

[77] van Donkelaar, C.E., Bakker, N.A., Veeger, N.J.G.M., Uyttenboogaart, M., Metzemaekers, J.D.M., Luijckx, G.-J., et al. (2015) Predictive Factors for Rebleeding after Aneurysmal Subarachnoid Hemorrhage: Rebleeding Aneurysmal Subarachnoid Hemorrhage Study. Stroke, 46, 2100-2106. https://doi.org/10.1161/STROKEAHA.115.010037

[78] Machiel Pleizier, C., Algra, A., Velthuis, B.K. and Rinkel, G.J.E. (2006) Relation between Size of Aneurysms and Risk of Rebleeding in Patients with Subarachnoid Haemorrhage. Acta Neurochirurgica (Wien), 148, 1277-1279. https://doi.org/10.1007/s00701-006-0911-5

[79] Mehta, L., Devlin, W., McCullough, P.A., O’Neill, W.W., Skelding, K.A., Stone, G.W., et al. (2007) Impact of Body Mass Index on Outcomes after Percutaneous Coronary Intervention in Patients with Acute Myocardial Infarction. American Journal of Cardiology, 99, 906-910. https://doi.org/10.1016/j.amjcard.2006.11.038

[80] Oreopoulos, A., Padwal, R., Kalantar-Zadeh, K., Fonarow, G.C., Norris, C.M. and McAlister, F.A. (2008) Body Mass Index and Mortality in Heart Failure: A Meta-Analysis. American Heart Journal, 156, 13-22.

https://doi.org/10.1016/j.ahj.2008.02.014

[81] Towfighi, A. and Ovbiagele, B. (2009) The Impact of Body Mass Index on Mortality after Stroke. Stroke, 40, 2704-2708. https://doi.org/10.1161/STROKEAHA.109.550228

[82] Schuss, P., Konczalla, J., Platz, J., Vatter, H., Seifert, V. and Güresir, E. (2013) Aneurysm-Related Subarachnoid Hemorrhage and Acute Subdural Hematoma: Single-Center Series and Systematic Review. Journal of Neurosurgery, 118, 984-990. https://doi.org/10.3171/2012.11.JNS121435

[83] Sandström, N., Yan, B., Dowling, R., Laidlaw, J. and Mitchell, P. (2013) Comparison of Microsurgery and Endovascular Treatment on Clinical Outcome Following Poor-Grade Subarachnoid Hemorrhage. Journal of Neurosurgery, 20, 1213-1218.

[84] Wong, G.K.C., Boet, R., Ng, S.C.P., Chan, M., Gin, T., Zee, B., et al. (2012) Ultra-Early (within 24 Hours) Aneurysm Treatment after Subarachnoid Hemorrhage. World Neurosurgery, 77, 311-315. https://doi.org/10.1016/j.wneu.2011.09.025

[85] Kao, L., Al-Lawati, Z., Vavao, J., Steinberg, G.K. and Katznelson, L. (2009) Prevalence and Clinical Demographics of Cerebral Salt Wasting in Patients with Aneu- 
rysmal Subarachnoid Hemorrhage. Pituitary, 12, 347-351.

https://doi.org/10.1007/s11102-009-0188-9

[86] Sherlock, M., O’Sullivan, E., Agha, A., Behan, L.A., Rawluk, D., Brennan, P., et al. (2006) The Incidence and Pathophysiology of Hyponatraemia after Subarachnoid Haemorrhage. Clinical Endocrinology, 64, 250-254. https://doi.org/10.1111/j.1365-2265.2006.02432.x

[87] Kim, D.K. and Joo, K.W. (2009) Hyponatremia in Patients with Neurologic Disorders. Electrolytes Blood Press, 7, 51-57.

[88] Adrogué, H.J. and Madias, N.E. (2000) Hyponatremia. The New England Journal of Medicine, 342, 1581-1589. https://doi.org/10.1056/NEJM200005253422107

[89] Ellis, S.J. (1995) Severe Hyponatraemia: Complications and Treatment. QJM-Monthly Journal of the Association of Physicians, 88, 905-909.

[90] Strange, K. (1992) Regulation of Solute and Water Balance and Cell Volume in the Central Nervous System. Journal of the American Society of Nephrology, 3, 12-27.

[91] McManus, M.L., Churchwell, K.B. and Strange, K. (1995) Regulation of Cell Volume in Health and Disease. The New England Journal of Medicine, 333, 1260-1266. https://doi.org/10.1056/NEJM199511093331906

[92] Nathan, B.R. (2007) Cerebral Correlates of Hyponatremia. Neurocritical Care, 6, 72-78. https://doi.org/10.1385/NCC:6:1:72

[93] Benvenuti, S., Deledda, C., Luciani, P., Modi, G., Bossio, A., Giuliani, C., et al. (2013) Low Extracellular Sodium Causes Neuronal Distress Independently of Reduced Osmolality in an Experimental Model of Chronic Hyponatremia. NeuroMolecular Medicine, 15, 493-503. https://doi.org/10.1007/s12017-013-8235-0

[94] Espay, A.J. (2014) Neurologic Complications of Electrolyte Disturbances and Acid-Base Balance. Handbook of Clinical Neurology, 119, 365-382.

https://doi.org/10.1016/B978-0-7020-4086-3.00023-0

\section{Abbreviations}

SAH-Subarachnoid hemorrhages, CT-Computed Tomography, DSA-Digital Subtraction Angiography, CSF-Cerebro-Spinal Fluid, CTA-Computed Tomographic Angiography, CTFG-Computed Tomography Fischer Grading, GOS-Glasgow outcome Scale, LP-Lumbar Puncture, mRS-modified Ranking Scale, GCS-Glasgow coma scale, H \& H Scale-Hunt and Hess Scale. 